\title{
A framework to use crop models for multi-objective constrained optimization of irrigation strategies
}

Bruno Cheviron ${ }^{\mathrm{a} \uparrow}$, , R. Willem Vervoort ${ }^{\mathrm{b}}$, Rami Albasha ${ }^{\mathrm{a}, \mathrm{c}, \mathrm{d}}$, Romain Dairon ${ }^{\mathrm{e}, \mathrm{f}}$, Camille Le Priol ${ }^{\mathrm{g}}$, Jean-Claude Mailhol ${ }^{\text {a }}$

a IRSTEA, UMR G-EAU, 361 rue Jean-François Breton, BP 5095, 34196 Montpellier Cedex 5, France.

${ }^{\mathrm{b}}$ Centre for Carbon, Water and Food, The University of Sydney, Australia.

${ }^{\mathrm{c}}$ INRA, UMR LEPSE, 2 Place Viala, 34060 Montpellier, France.

${ }^{\mathrm{d}}$ Department of Water Sciences, faculty of Civil Engineering, University of Aleppo, Ibn-Albitar Street, Aleppo, Syria.

${ }^{\mathrm{e}}$ IRSTEA, UR MALY, Centre de Lyon, 5 rue de la Doua, CS70077, 69626 Villeurbanne Cedex 5, France.

${ }^{\mathrm{f}}$ INRA, UMR Agroecologie, 17 rue Sully, BP86510, 21065 Dijon Cedex, France.

${ }^{g}$ SupAgro Montpellier, 2 Place Viala, 34060 Montpellier, France.

${ }^{\dagger}$ Corresponding author.

e-mail: bruno.cheviron@irstea.fr

phone number: +33(0)4 67046364

fax number: +33(0)4671664 40 


\section{Abstract}

This paper discusses an innovative framework to use crop models which combines sensitivity analysis, uncertainty analysis and constrained optimisation runs for irrigation optimisation purposes, facing competing constraints on several agricultural variables (e.g. crop yield, total irrigation amount, financial expectations). For simplicity, this ex-post optimisation relies on direct calculations only, exploiting the dispersions on the target variables. The screening of the parameter space for sensitivity analysis yields a reference dispersion which is expectedly reduced by reducing the uncertainties in the sensitive parameters and/or climatic forcings. Additional dispersions are calculated to evaluate if the management controls on irrigation strategies (amounts, triggers, periods) are more influential on model predictions than the remaining uncertainties on the soil, plant, irrigation and climatic inputs, eventually allowing optimisation. As a case study, the Optirrig model is used. A discussion proposes future ways to convert diagnostics into real-time near-optimal decision rules, for example through learning algorithms.

\section{Highlights}

- This ex-post optimization of irrigation strategies involves direct calculations only

- The Optirrig model (Irstea Montpellier, France) is chosen for application

- Both the feasibility and the achievement of irrigation optimization are handled

- Dispersion is reduced through sensitivity, uncertainty then optimization runs

- Perspectives are discussed to convert diagnostics into real-time decision rules

\section{Keywords}

Crop model, optimisation, modelling, scenarios, framework, uncertainty analysis.

\section{Software availability}

Neither the Optirrig model nor the presented irrigation optimization code are downloadable as opensource material, due to the licensing strategy of Irstea (the French National Research Institute of Science and Technology for Environment and Agriculture). Both have been developed in FORTRAN but will be recoded in Python: a new Graphical User Interface is planed and the software will be distributed at this time. Contact: bruno.cheviron@irstea.fr 


\section{Introduction}

Crop models aim to predict agricultural yields from selected soil properties, plant characteristics and climatic forcings, and possibly dependent on irrigation strategies. Even if they are of limited extent, the random uncertainties in source data (Nonhebel 1994, Aggarwal 1995, Heinemann et al. 2002, Rivington et al. 2006, Spank et al. 2013) can combine and propagate through the models, whose predictions should therefore include statistical confidence intervals or at least relevant, dedicated estimates of the error terms or trends affecting model outputs (Monteith 1996, Challinor et al. 2009, 2010, Wallach et al. 2012, Asseng et al. 2013). Noticeable differences exist between model structures, purposes and responses, especially for climate change scenarios, hence the difficulty to decipher absolute, normative evaluations. This, in turn, outlines the interest in model intercomparison methodologies (Rötter et al. 2011, White et al. 2011, Asseng et al. 2013) that help positioning any tested model among possible alternatives or help choosing between several candidate models.

Whatever the selected model, model exploration, sensitivity analysis and uncertainty assessment always need intensive calculations which typically fall within the scope of model automation procedures: these can then provide both the agricultural scenarios and their associated dispersion envelopes. As a result the optimisation of irrigation strategies consists of comparing what may be gained from appropriate resources management, taking into acount the dispersion in model predictions that arises from intrinsic uncertainties in source data, or from hypotheses of climate change and increased variability (Rosenzweig \& Parry 1994, Rosenzweig et al. 2014) with the associated deficit irrigation issues (English 1990, Reca et al. 2001, Pereira et al. 2002, Geerts \& Raes 2009). Several simulation platforms have been developed in the recent years, based on some of the most popular crop models. However, agronomical modelling still seems to miss a framework that relies on model automation to propose successive steps towards the identification of the context-dependent best irrigation strategies. Moreover, these "multi-variable constrained optimisation" strategies can be inferred from objective functions that not only rely on crop yield levels (Sun et al. 2006, Cetin \& Uygan 2008).

Advances in computer science have facilitated the automation of crop models. For example, the connection to environmental and socio-economic issues, with a clear trend to use biophysical models within integrated system and economic viability assessment (Vatn et al. 1999, Berntsen et al. 2003, Belcher et al. 2004, Janssen \& van Ittersum 2007). In addition, the inclusion of crop models in simulation platforms related to communication between models based on common databases or input/output formats. For example, AqYield (Nolot \& Debaeke 2003, Murgue et al. 2014, Constantin et al. 2015) may now be run on the MAELIA platform (Gaudou et al. 2013) to handle low-water 
management issues and multi-agent spatial planning, STICS (Brisson et al. 2003, 2009) runs on the RECORD platform (Bergez et al. 2013) that integrates farming practices into agro-ecosystems and APSIM (McCown et al. 1995, Keating et al. 2003) now embeds the PMF - Plant Modeling Framework (Brown et al. 2014) as a sub-model. Not long ago, the Harvestchoice (2010) platform already allowed scenarios and regional-scale decision-making on the basis of data issued from APSIM or DSSAT (Jones et al. 2003). Other composite (SAFYE, Duchemin et al. 2006, 2008) or generic crop models (RZWQM, Hanson et al. 1998, Ma et al. 2006) offer many of the above possibilities, while Aquacrop (Steduto et al. 2009, Raes et al. 2009) was used in combination with an economic model to optimise irrigation management (García-Vila \& Fereres 2012). Irrigation management, as a part of ecosystem responses to climate changes, has been addressed by APSIM (Ludwig \& Asseng 2006), WOFOS (Wolf \& van Diepen 1995, Reidsma et al. 2009, Supit et al. 2012), RZWQM (Ko et al. 2011, Islam et al. 2012) and STICS (Singh et al. 2014), among others.

Finally, a typical evolution through the last decades is that of the Wageningen crop models (e.g. WOFOS, van Diepen et al. 1989, Boogaard et al. 1998, van Ittersum et al. 2003) from their original formulations in the 1980's (often in FORTRAN 77) to object-oriented and modular programming structures (e.g. PCSE - Python Crop Simulation Development, de Wit 2015) at the assumed risk of slower model execution. In summary, what is sought in general is (i) simulation engines running multi-agent scenarios, (ii) the flexibility of modular designs that use crop models as plug-ins and (iii) interfaces between models based on common exchange file formats. The framework presented here is compatible with such approaches as (i) it offers the possibility to perform multi-objective constrained optimisation from the analysis of a wide variety of user-defined irrigation scenarios, (ii) most of the automated crop models fit in this framework, provided (iii) they communicate through input/output text files. The newly-automated version of the Optirrig model (formerly the PILOTE model, Mailhol et al. 1997; Khaledian et al. 2009; Mailhol et al. 2011, Feng et al. 2014) has been chosen here for application of the proposed framework, providing guidelines for the identification of optimal irrigation parameters from successive direct calculations (sensitivity analysis, uncertainty analysis then constrained optimisation runs) associated with decreasing dispersion on the target variables (i.e. convergence towards one or several equifinal parameter sets).

Section 2 of this paper highlights the successive stages of the framework that leads to the multiobjective constrained optimisation of irrigation strategies, across preliminary sensitivity and uncertainty analyses, also indicating ways to evaluate the effect of management decisions versus parameter and forcing uncertainties (Section 2.1). For simplicity, the Optirrig model developed at Irstea is chosen for these applications (Section 2.2) but the framework was designed to be as generic as possible. Section 3 presents the results of the sensitivity analysis (Section 3.1), uncertainty analysis 
(Section 3.2) and constrained optimisation runs (Section 3.3). The discussion (Section 3.4) highlights the specificities, strengths and limitations of this framework (Section 3.4.1) as well as possible adaptations for the search of real-time near-optimal decision rules (Section 3.4.2). Section 4 is the conclusion.

\section{$2 \quad$ Material and methods}

\subsection{Framework for multi-objective constrained optimisation}

\subsubsection{Scope and overview}

This framework indicates how to perform scenarios of agricultural yield from irrigation strategies (e.g. dates, doses, trigger criteria), acknowledging uncertainties on both the model parameters (e.g. soil and plant parameters) and its climatic forcings (e.g. rain, potential evapotranspiration, radiation and temperature), possibly handling hypotheses of climate change and variability. However, irrigation optimisation is defined here as extracting the user-defined best cases from a series of scenarios, which typically requires the definition of one or several objective functions, in addition to the agricultural yield $(\mathrm{Y})$. Other candidates are the total irrigation amount (I), the irrigation water use efficiency (IWUE) and an economic cost function related to financial expectations (F) that combines the selling price of the harvested crop and the cost of the irrigation water. In the following, a multi-objective constrained optimisation framework targets these variables, calculated by most crop models. Figure 1 shows an overview of this framework, that involves three successive run series (A. Sensitivity analysis: Subsection 2.1.2, B. Uncertainty analysis: Subsection 2.1.3 and C. Constrained optimisation: Subsection 2.1.4) with five stages in each series (Stage 1- Conceptual case preparation, Stage 2Technical case preparation, Stage 3-Controls and settings, Stage 4- Calculation loop and Stage 5Post-treatments). The description of the stages is the same whatever the run series.

Stage 1 is where the modeller builds a mental model of the problem and selects a strategy to address it. The subsequent stages are all automated, provided (i) an automated version of the crop model is available, (ii) it uses a single parameter file (where parameter sets to process appear on successive lines in this file) and (iii) it uses a climate file in which the values of forcings in time appear in columns. Although not shared by all crop models, these requirements were found sufficiently easy to meet to justify the automation of the other stages. 
Stage 2 is where the selected scenarios are encoded in source files.

- If the scenarios decided in Stage 1 do not involve random perturbations (neither of the parameters nor of the forcings) then the automated model will run (in Stage 4) on the parametric scenarios previously placed in its parameter file, using the current climate file.

- If random perturbations are intended, then the user indicates whether they should apply to model parameters or to climatic forcings. In the latter case, this is stored in an auxiliary file together with the relative or absolute magnitudes allowed for the uncertainties, supposed to affect each of the climatic data (e.g. rain, potential evapotranspiration, radiation and temperature for the Optirrig model). The procedure does not generate a series of perturbed climate files from the existing climate file. It generates and applies random perturbations (and stores them elsewhere) for the selected forcings, in the predefined ranges, each time the climate file is read, that is, each time the model is called in the calculation loop (Stage 4). This avoids memory issues. The process is different when the user asks for random perturbations of model parameters. In this case, the selected parameters are randomly perturbed, in predefined ranges, from the values appearing in the reference parameter set. This causes the generation of a new parameter file, whose parameter lines will be read, one after the other, during the calculation loop (Stage 4).

Stage 3 is where the working directory is cleaned up to avoid name confusions and files overwriting. The counters are reset (these counters are used for automated naming of the output files) and the communication files are prepared. Stage 4 is where the command-line version of the model is run repeatedly until the $n$ intended runs have been processed (either the model has already been automated or is available in its command-line version to fit in this framework). Most models provide timevariable as well as seasonal results, often within dedicated output files. This framework requires the existence (or assembly) of two output files, in text format. Although not very flexible, this option was found general enough to deal with the outputs of most models, sometimes with the help of an auxiliary program to rewrite model outputs in the required program. The "seasonal file" should display all model outputs, for each simulation, on a single line, so that $n$ scenarios will result in as many result lines in the seasonal file. By contrast, the "time-variable file" should be organized in columns, each column containing the evolution of a selected model output with time. Stage 5 is where posttreatments (decided in Stage 1) are applied to model outputs. These default to basic statistics (including dispersion and confidence intervals) on the outputs unless otherwise specified by the user. 


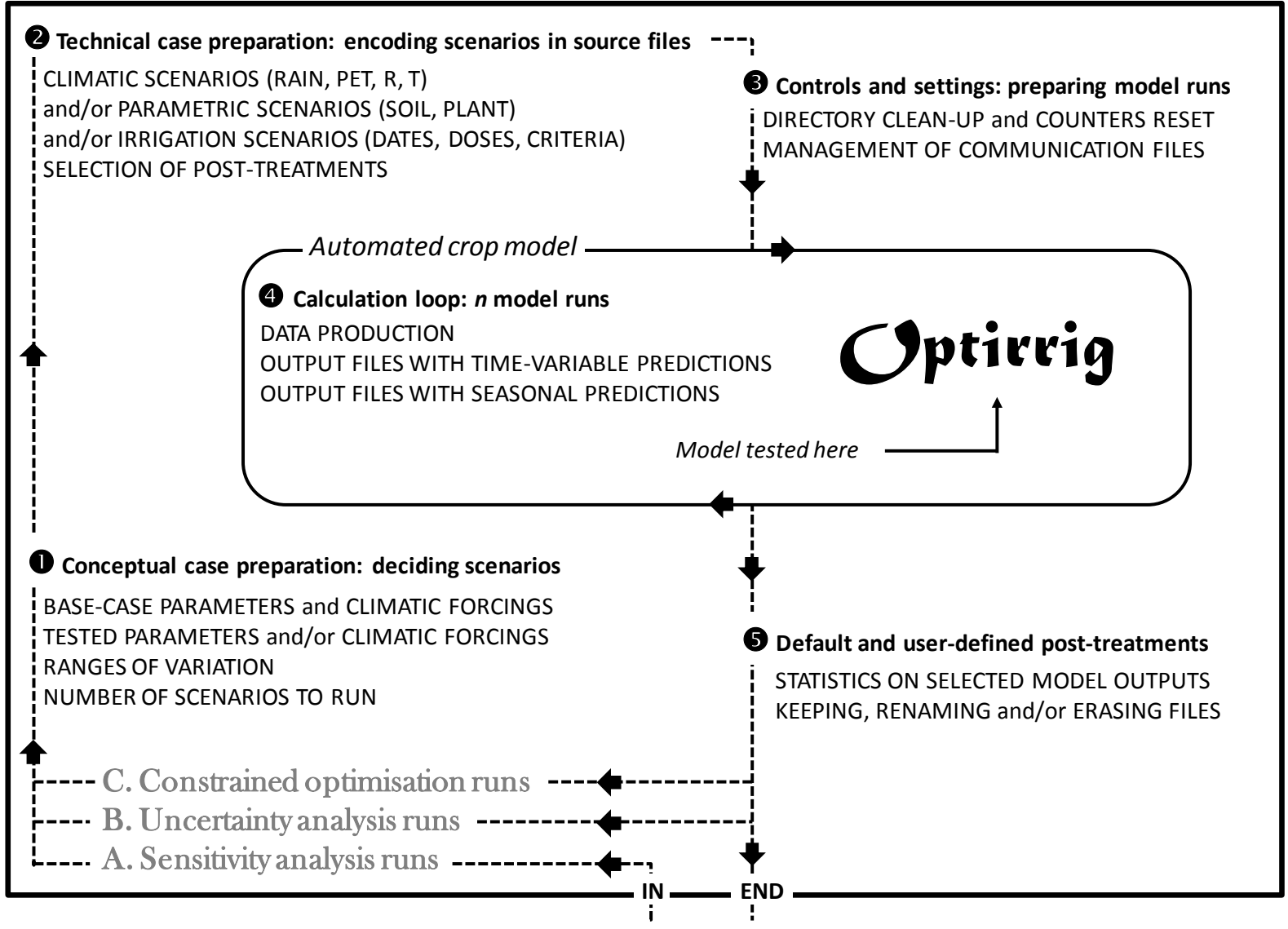

Figure 1 - Conceptual five-stage view of the framework that relies on three distinct, successive series of sensitivity analysis (A), uncertainty analysis (B) and constrained optimisation (C) runs . The model tested here is Optirrig, developed and automated at IRSTEA, the French National Research Institute of Science and Technology for Environment and Agriculture. Each run series comprises Stage 1- Conceptual case preparation, Stage 2- Technical case preparation, Stage 3- Controls and settings, Stage 4- Calculation loop and Stage 5- Post-treatments. 


\subsubsection{Sensitivity analysis runs}

This preliminary sensitivity analysis is suggested to discard the parameters that show no significant effect on the results. In the large set of local (near a reference point in parameter space), multilocal (near a few selected points) and global (screening of the whole parameter space) sensitivity analysis methods, possibly applied for model verification and sensitivity assessment, the Morris (1991) method belongs to the category of multilocal methods. It allows more local and deterministic results than the extensive but "blind" Monte-Carlo methods (e.g. Sieber \& Uhlenbrook 2005) or global variance-based methods as for example the Sobol (1993) or FAST (Fourier Amplitude Sensitivity Test, Helton 1993) methods. As elsewhere in the literature of environmental modelling (e.g van Griensven et al. 2006, Mulungu \& Munishi 2007) this method is suitable to explore selected parameter ranges near selected model configurations (i.e. not aiming at thorough model verifications thus hypothesizing the tested model has already been proven robust, at least for the tested intervals of parameter values). The choice of the Morris method is therefore convenient (though non-unique, as other user-defined alternatives may exist) to perform the intended preliminary sensitivity analysis and also to yield the associated $\left(\mathrm{d}_{0}\right)$ reference dispersion of model results, which is the starting point of the optimisation framework in this paper.

The Morris method was designed to save calculation time by performing a limited though relevant exploration of the parameter space, as described by Campolongo \& Saltelli (1997). Improvements by Campolongo et al. (2007) included a slightly different generation of the trajectories in the parameter space to derive the sensitivity measures and a slightly different definition of the sensitivity measures themselves. The objective of the modified Morris method is to identify which parameters have (i) a negligible influence on model results and may thus be fixed, (ii) a linear influence (when there is a clear correlation between model results and the value of the tested parameter, whatever the values of the other parameters) or (iii) a non-linear influence (when a parameter is more influential through interactions with other parameters and/or when the model has a non-linear response to variations of the tested parameter). However, both sensitivity measures and the calculated reference dispersion $\left(\mathrm{d}_{0}\right)$ likely depend on the climatic forcings and assumed uncertainties. For example the parameters associated with soil water content or uptake (e.g. rooting depth, field capacity, wilting point) will certainly become more sensitive when less water is present, for example for abnormally dry years. On the one hand this framework cannot provide information on how to classify the climatic forcings (e.g. into dry, reference and wet years, with all possible variations). On the other hand the framework is only valid if its successive run series ("A: Sensitivity, B: Uncertainty, C: Constrained optimisation" in Figure 1) are undertaken for the same climatic forcings. This leaves the possibility of seeking climatedependent optimisation from different recorded or generated climatic forcings. 


\subsubsection{Uncertainty analysis runs}

The uncertainty analysis complements the previous sensitivity analysis. It focuses on the sensitive model parameters and on the climatic forcings. The first aim is to roughly quantify the link between the uncertainties of the inputs (model parameters and/or forcings) and the dispersion of the outputs (daily state variables and seasonal predictions). The second aim, and practical objective, is to identify which uncertainties should be reduced to make model predictions "accurate enough", for example standard deviation less than $0.1 \mathrm{t} \mathrm{ha}^{-1}$ on the predicted crop yield or 90\%-confidence interval less than $10 \%$ of the predicted yield. The sensitivity analysis indicates which parameters have the strongest linear or non-linear influences and may be useful for "individual" or "collective" gains in precision, but it does not indicate which of these calibration, field or literature parameters are easily accessible (and improvable) and which are not. Similar questions appear regarding the need (and feasibility) of improving the precision of the climatic records. Whatever the decisions made, the associated costs may become part of the modelling strategy and be propagated through the rest of the framework. The third aim is to prepare a reliable multi-objective constrained optimisation. Narrower dispersion envelopes on model predictions tend to ensure that management options (i.e. irrigation strategies simulated through multiple combinations of dedicated parameters) are more influential on the results than the remaining uncertainties. To check this the dispersion caused by the uncertainties $\left(d_{1}\right)$, the dispersion caused by the uncertainties and the management strategies $\left(\mathrm{d}_{2}\right)$ and the dispersion caused by the uncertainties, the management strategies and the uncertainties affecting them $\left(d_{3}\right)$ have to be compared. A favourable situation for the optimisation is $d_{3} \approx d_{2}>d_{1}$. In accordance, one also would expect $d_{0}>d_{1}$, where $d_{0}$ is the original dispersion associated with the parameter ranges tested in the preliminary sensitivity analysis. These filters (or criteria) are deliberately loose in their definition, so that the modeller has to adjust each of them depending on the context of the study (for example by deciding if $d_{2}>>d_{1}$ is required instead of $d_{2}>d_{1}$ or conversely if $d_{2} \geq d_{1}$ is enough). However, in the proposed framework, it is the succession of criteria that is thought to be generic enough to provide the modeller with enough degrees of freedom to correctly design the optimisation problem.

This section therefore involves multiple series of "Uncertainty analysis runs" (Figure 1). Each run series involves generating a "large enough" (for statistical reliability) parameter file in which the values of the sensitive parameters have been randomly perturbed, within user-defined ranges around their reference, base-case values. For this test case, the sampling strategy consisted of dividing parameter ranges into $\mathrm{q}=8$ quantiles and started from $\mathrm{r}=100$ randomly drawn parameter combinations resulting in $m=2900$ model runs to test $n=28$ parameters, from the known relation $m=r^{*}(n+1)$. For comparison purposes, the classical choice (Campolongo et al. 2007) is $q=4$ and $r=10$ but the larger 
values of $\mathrm{q}$ and $\mathrm{r}$ tested here allow more reliable ranking of the sensitivity measures, provided the calculation time is not a limiting factor. More technical details and comparisons between the "MonteCarlo type" families of sensitivity analysis methods can be found in Yang et al. (2011) or Gan et al. (2014) for environmental applications. These studies suggest other stratified random sampling strategies as Latin Hypercube (McKay 1988, modified by van Griensven et al. 2006), Orthogonal Array (Owen 1992) or Orthogonal Array-based Latin Hypercube (Tang 1993) are valuable "multilocal" alternatives to the Morris (1991) method. The parameter ranges should be chosen in accordance with the three above aims, which also holds for the uncertainties on the climatic forcings.

\subsubsection{Constrained optimisation runs}

Multi-objective constrained optimisation is based on identifying the management options (i.e. irrigation strategies) that best meet predefined contradictory constraints on selected model outputs (e.g. a minimal yield level $\mathrm{Y}>\mathrm{Y}_{\mathrm{C}}$, a maximal irrigation quota $\mathrm{I}<\mathrm{I}_{\mathrm{C}}$ and a profitable-enough site management $\mathrm{F}>\mathrm{F}_{\mathrm{C}}$ ). In contrast with the other parameter categories ("Plant", "Soil", "Temperature", later described) or climatic forcings, parameters associated with irrigation strategies are not random. Their values correspond to deliberate strategies (e.g. applying small amounts but frequently or large amounts about weekly) provided these strategies are not blurred by the uncertainties of the associated parameters (e.g. measuring the irrigation amounts ). As the optimisation includes handling the irrigation strategies and their uncertainties, both have been included in the "management controls" category of parameters: optimisation is eventually achieved by controlling the amount of uncertainty that affects the optimal parameter sets.

Most crop models offer several possible management controls on the irrigation strategy, through a series of dedicated parameters. These are, for example, the choice of a fixed or adaptive irrigation calendar, the choice of a threshold soil water reserve that triggers irrigation, that of the irrigation amount (i.e. the water amount to apply at each irrigation) or that of an irrigation window (i.e. a time period within which irrigation is allowed, which eventually simulates legal issues in water allocation or availability). The question raised with the multi-objective constrained optimisation of irrigation strategies is deliberately wider than a maximum possible increase in agricultural yield. It introduces the interplay between the total irrigation amount (I), the agricultural yield (Y) and the irrigation water use efficiency (IWUE) in the variations of a more global variable such as the financial expectations (F). These (simplistic) expectations subtract the cost of irrigation water from the selling price of maize. Although very naive in its formulation, it was found to open ways for numerous possible uses of this framework and was thus kept throughout the next sections, constituting a set of four (I, Y, IWUE, F) targets, as seasonal variables to be used in the definition of appropriate objective functions. 
Table 1 summarizes the framework from the preliminary sensitivity analysis to the constrained optimisation, highlighting the successive measures of dispersion to provide guidance on how to use at best the various run series of the framework (Figure 2).

\begin{tabular}{|c|c|c|c|c|}
\hline Run series & Dispersion & Description & Criteria & Favourable case \\
\hline $\begin{array}{l}\text { A. Sensitivity } \\
\text { analysis }\end{array}$ & $\mathrm{d}_{0}$ & $\begin{array}{c}\text { Arises from the method used to screen the } \\
\text { parameter space, for assumed parameter ranges } \\
\text { and uncertainties on the climatic forcings. }\end{array}$ & None. & $\begin{array}{c}\text { Large } \mathrm{d}_{0} \text { and } \\
\text { non linear } \\
\text { sensitivities }\end{array}$ \\
\hline \multirow[t]{3}{*}{$\begin{array}{l}\text { B. Uncertainty } \\
\text { analysis }\end{array}$} & $\mathrm{d}_{1}$ & $\begin{array}{l}\text { Obtained from reduced uncertainties on the } \\
\text { sensitive parameters and/or climatic forcings. }\end{array}$ & $\begin{array}{c}\text { Semi-quantitative }: \mathrm{d}_{1}<\mathrm{d}_{0} \text { and/or weak } \\
\text { dispersion on the predictions of daily or } \\
\text { seasonal model variables (e.g. } 95 \% \\
\text { confidence interval }<25 \% \text { of the predicted } \\
\text { yield). }\end{array}$ & $\mathrm{d}_{1} \ll<\mathrm{d}_{0}$ \\
\hline & $\mathrm{d}_{2}$ & $\begin{array}{l}\text { Corresponds to } d_{1}+\text { the dispersion associated } \\
\text { with possible, deliberate irrigation strategies. }\end{array}$ & $\begin{array}{l}\text { Semi-quantitative : } \mathrm{d}_{2}>\mathrm{d}_{1} \text { suggests that the } \\
\text { effects of irrigation strategies can prevail } \\
\text { over these of parameter uncertainties }\end{array}$ & $\mathrm{d}_{2} \approx \mathrm{d}_{0}$ \\
\hline & $\mathrm{d}_{3}$ & $\begin{array}{l}\text { Corresponds to } d_{2}+\text { the dispersion associated } \\
\text { with uncertainties on the irrigation parameters. }\end{array}$ & $\begin{array}{c}\text { Semi-quantitative : } \mathrm{d}_{3} \approx \mathrm{d}_{2} \text { suggests negligible } \\
\text { effects of the uncertainties on irrigation } \\
\text { parameters. }\end{array}$ & $\mathrm{d}_{3} \approx \mathrm{d}_{2} \approx \mathrm{d}_{0}$ \\
\hline $\begin{array}{l}\text { C. Constrained } \\
\text { optimisation }\end{array}$ & $\mathrm{d}_{4}$ & $\begin{array}{c}\text { Dispersion that affects the optimal solutions and } \\
\text { possibly makes them suboptimal. Back- } \\
\text { calculated as the effects of uncertainties on the } \\
\text { irrigation parameters and climatic forcings }\end{array}$ & $\begin{array}{c}\text { Quantitative : user-defined contradictory } \\
\text { constraints on several seasonal output } \\
\text { variables (e.g Irrigation } \mathrm{I}<\mathrm{I}_{\mathrm{C}}, \text { Yield } \mathrm{Y}<\mathrm{Y}_{\mathrm{C}} \text {, } \\
\text { Financial expectations } \mathrm{F}<\mathrm{F}_{\mathrm{C}} \text { ) }\end{array}$ & $\mathrm{d}_{4} \rightarrow 0$ \\
\hline
\end{tabular}

Table 1 - Guidelines and good practices for the present framework, across successive run series (sensitivity analysis, uncertainty analysis, constrained optimisation runs) and the associated measures of dispersion in model predictions, relying on user-defined semi-quantitative or quantitative criteria. The "Favourable case" columns indicates the situations in which the advocated optimisation procedure is needed and expected to perform well.

\subsection{The Optirrig model}

This section presents an overview of model rationale and structure, described in details by Mailhol et al. (1997, 2011). Optirrig (formerly PILOTE) is a simplified three-reservoir hydrological model coupled to a crop model. Its principle, original, feature is to use the leaf area index as a proxy for crop yield (or strictly speaking as the quantity from which the total dry matter and agricultural yield are derived). Figure 2 shows the organisation of the climatic forcings, parameters, intermediate variables and key state variables (Leaf Area Index: LAI, Total Dry Matter: TDM, crop Yield: Y) in Optirrig's main calculation loop. To avoid redundancy, the meaning of the model parameters is only given in Section 3 (Table 2) prior to the sensitivity and uncertainty analyses. 


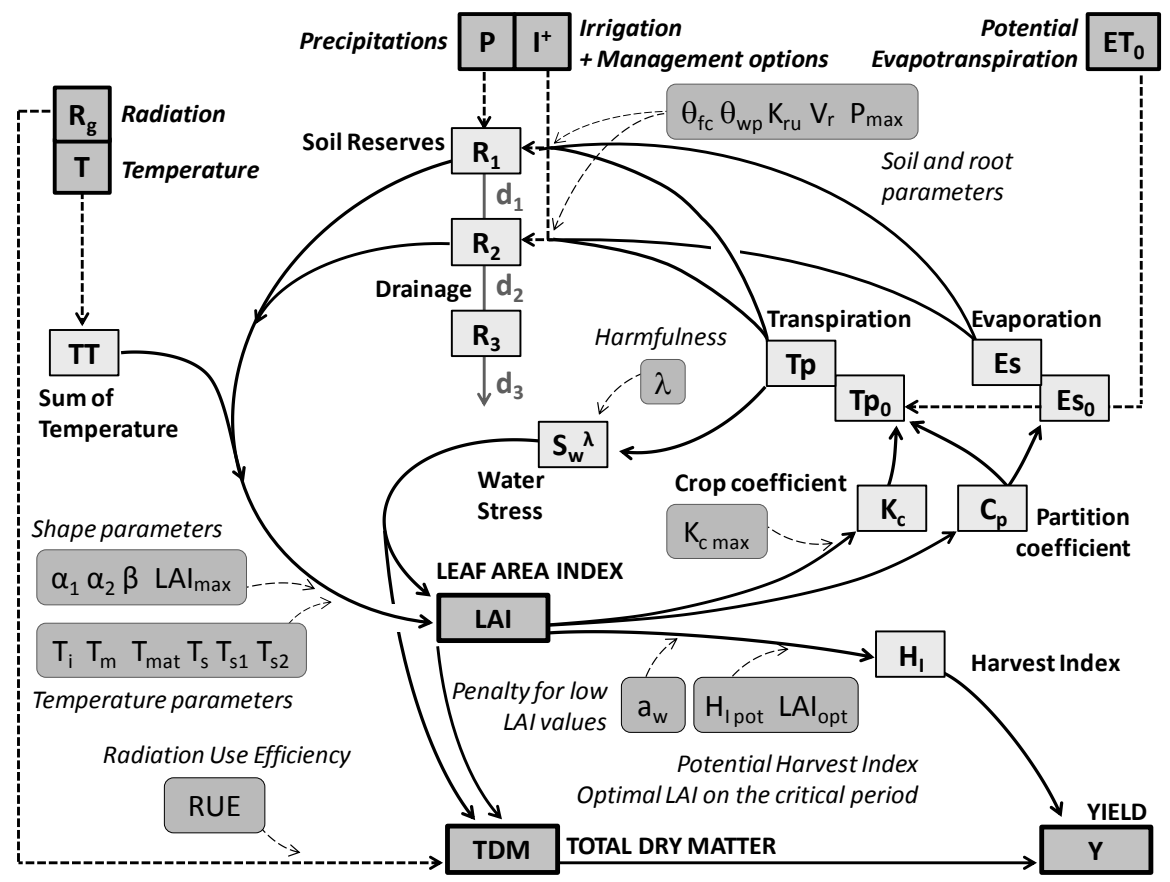

Figure 2 - The structure and principle of the Optirrig model, showing the organisation of climatic forcings (squares with thick contour lines), parameters (boxes with rounded contour lines), intermediate variables (pale grey sketches) and key state variables (grey sketches with thick contours: LAI, TDM and Y). Irrigation is noted I+ to indicate that this model forcing depends on multiple management options and associated parameters.

The case study is for maize, at Lavalette experimental station (Montpellier, South of France), in 2011, under sprinkler irrigation (unpublished data, available from the IRSTEA database) in a "nearly full ETM treatment" (ETM for maximal evapotranspiration), that is applying enough irrigation for the crop to approach the best possible yield values, without going through a real optimisation procedure. The soil is predominantly loamy on the study site, ranging from loamy sand in the first horizon to silt-loam in the third. Table 2 gives the full set of base-case (reference) parameter values as a starting point for the various scenarios and tests. Table 2 also lists the perturbations applied, indicating the assumed range of values for each of the tested parameters. For simplicity, no uncertainty was supposed to affect the climatic forcings in the present application: previous analyses have shown that hypothesized nonnegligible uncertainties of $+/-7.5 \%$ on each of the climatic forcings (climatic demand, incoming radiation, rain and temperature) did not result in significant effects when compared to (or tested in combination with) the variation ranges and uncertainties of model parameters. However, all run series can easily be carried out with uncertainties on both the climatic forcings and model parameters. 


\begin{tabular}{|c|c|c|c|c|c|c|}
\hline Category & Code & Name & Description & Reference & Range & Units \\
\hline \multirow[t]{11}{*}{ Plant (P) } & P1 & $a_{w}$ & Controls the decrease of $\mathrm{H}_{\mathrm{I}}$ for low LAI values & 0.12 & $+/-10 \%$ & - \\
\hline & $\mathrm{P} 2 *$ & $\mathrm{H}_{\mathrm{I} \text { pot }}$ & Potential $\mathrm{H}_{\mathrm{I}}$ (Harvest Index) & 0.52 & $+/-7.5 \%$ & - \\
\hline & $\mathrm{P} 3 *$ & $\mathrm{~K}_{\mathrm{c} \max }$ & Maximum value of $\mathrm{K}_{\mathrm{c}}$ (crop coefficient) & 1.20 & $+/-10 \%$ & - \\
\hline & P4 & $\mathrm{LAI}_{\max }$ & Maximum LAI value & 5.00 & $+/-7.5 \%$ & - \\
\hline & P5 & $\mathrm{LAI}_{\mathrm{opt}}$ & Supposed $\mathrm{H}_{\mathrm{I}}$-optimal LAI value & 2.50 & $+/-10 \%$ & - \\
\hline & P6 & $\mathrm{G}_{\mathrm{hu}}$ & Percentage of grain humidity & 15 & $+/-33 \%$ & \\
\hline & P7 & RUE & Radiation Use Efficiency & 1.35 & $+/-7.5 \%$ & - \\
\hline & P8* & $\alpha_{1}$ & First shape parameter for LAI curves & 2.50 & $+/-15 \%$ & - \\
\hline & P9 & $\alpha_{2}$ & Second shape parameter for LAI curves & 1.00 & $+/-15 \%$ & - \\
\hline & P10* & $\beta$ & Third shape parameter for LAI curves & 2.50 & $+/-15 \%$ & - \\
\hline & P11* & $\lambda$ & Harmfulness of the water stress & 1.25 & $+/-10 \%$ & - \\
\hline \multirow[t]{5}{*}{ Soil (S) } & S1 & $\mathrm{K}_{\mathrm{ru}}$ & Easily usable reserve / field capacity & 0.66 & $+/-7.5 \%$ & - \\
\hline & $\mathrm{S} 2$ & $\mathrm{P}_{\max }$ & Maximum profile and rooting depth & 1.20 & $+/-7.5 \%$ & $\mathrm{~m}$ \\
\hline & $\mathrm{S} 3 *$ & $\mathrm{~V}_{\mathrm{r}}$ & Root growth rate & 1.50 & $+/-10 \%$ & $\mathrm{~cm} \mathrm{~d}^{-1}$ \\
\hline & S4* & $\theta_{\mathrm{fc}}$ & Field capacity & 0.29 & $+/-7.5 \%$ & - \\
\hline & S5* & $\theta_{\mathrm{wp}}$ & Wilting point & 0.12 & $+/-7.5 \%$ & - \\
\hline \multirow[t]{6}{*}{ Temperature $(\mathrm{T})$} & $\mathrm{T} 1$ & $\mathrm{~T}_{\mathrm{i}}$ & Temperature sum for root installation & 150 & $+/-7.5 \%$ & ${ }^{\circ} \mathrm{C}$ \\
\hline & $\mathrm{T} 2 *$ & $\mathrm{~T}_{\mathrm{m}}$ & Temperature sum to reach the maximum LAI & 1300 & $+/-5 \%$ & ${ }^{\circ} \mathrm{C}$ \\
\hline & T3 & $\mathrm{T}_{\text {mat }}$ & Temperature sum for crop maturity & 2050 & $+/-5 \%$ & ${ }^{\circ} \mathrm{C}$ \\
\hline & $\mathrm{T} 4 *$ & $\mathrm{~T}_{\mathrm{s}}$ & Temperature sum for crop emergence & 100 & $+/-10 \%$ & ${ }^{\circ} \mathrm{C}$ \\
\hline & T5 & $\mathrm{T}_{\mathrm{s} 1}$ & Temperature sum for the $1^{\text {st }}$ critical stage & 900 & $+/-10 \%$ & ${ }^{\circ} \mathrm{C}$ \\
\hline & T6 & $\mathrm{T}_{\mathrm{s} 2}$ & Temperature sum for the $2^{\text {nd }}$ critical stage & 1700 & $+/-10 \%$ & ${ }^{\circ} \mathrm{C}$ \\
\hline \multirow[t]{7}{*}{ Management (M) } & M1* & - & Irrigation dose (applied at each irrigation) & 30 & $20-40$ & $\mathrm{~mm}$ \\
\hline & M2 & - & Dose applied at sowing & 30 & $25-35$ & $\mathrm{~mm}$ \\
\hline & M3 & - & Soil reserve when starting the simulation & 300 & Fixed & $\mathrm{mm}$ \\
\hline & M4* & - & Period allowed for irrigation (in days after sowing) & 140 & $120-160$ & - \\
\hline & M5 & - & "Mulch effect": Evaporation Es -> Es/(1+M5) & 0 & $0-1$ & - \\
\hline & M6* & - & Sowing day & 114 & $104-124$ & - \\
\hline & M7* & - & Water reserve $\mathrm{RATIO}^{\dagger}$ that triggers irrigation & 62.5 & $53-72$ & $\%$ \\
\hline
\end{tabular}

$\dagger$ The RATIO variable denotes the filling percentage of the root zone reserve, plotted in Fig.5.

Table 2 - List of main source data required to run the model, with their associated category, code, name, description, reference value, range tested in sensitivity analysis and units. Data have been sorted into the P: Plant, S: Soil, T: Temperature and M: Management controls categories. The * symbol indicates parameters kept for scenarios generation after the preliminary sensitivity analysis. The listed reference values pertain to maize, under sprinkler irrigation, on the IRSTEA experimental site of Lavalette (Montpellier, France). 


\section{$3 \quad$ Results and discussion}

\subsection{Sensitivity analysis runs}

Figure 3 shows the preliminary sensitivity results. Figure 3 a displays the starting (or original) $\mathrm{d}_{0}$ dispersion associated with the 2900 model runs (along the $\mathrm{x}$-axis) undertaken for model exploration, combining variations in parameters for the $\mathrm{P}, \mathrm{S}, \mathrm{T}$ and $\mathrm{M}$ categories in Table 2, sorting results by increasing crop yield values (along the y-axis). Besides crop yield (Y), the chosen target variables for analysis were the total irrigation amount (I) and the associated Irrigation Water Use Efficiency (IWUE). This was defined as IWUE $=\left(\mathrm{Y}-\mathrm{Y}_{\mathrm{RF}}\right) / \mathrm{I}$ where $\mathrm{Y}_{\mathrm{RF}}$ is the yield obtained in rainfed conditions (not to be confused with $\mathrm{Y}_{\mathrm{REF}}$ where the subscript designates a result obtained from the reference model parameterisation). The reference scenario with values indicated in Table 2 resulted in $\mathrm{Y}_{\mathrm{REF}}=15.1$ ton $\mathrm{ha}^{-1}$ with $\mathrm{I}=510 \mathrm{~mm}$ (apart from the $30 \mathrm{~mm}$ irrigation at sowing time) while the rainfed hypothesis yielded $\mathrm{Y}_{\mathrm{RF}}=5.4$ ton ha ${ }^{-1}$, a typical value for local conditions. The IWUE $E_{\mathrm{REF}}$ value calculated from $Y_{\text {REF }}$ is thus $19 \mathrm{~kg} \mathrm{ha}^{-1} \mathrm{~mm}^{-1}$. Financial expectations $(\mathrm{F})$ have been added to the target variables. A cost of $0.7 € \mathrm{~m}^{-3}$ cost for water delivery and use was applied together with a $210 €$ ton $^{-1}$ selling price for maize, based on local data, to provide an estimate of $\mathrm{F}$ for each tested case. This made $\mathrm{F}$ a function of $\mathrm{I}, \mathrm{Y}$ and IWUE, hypothesizing that $\mathrm{Y}$ considered alone may provide a trend but is probably not the key indicator for F values, which is confirmed by Figure 3a. These estimated values of $\mathrm{F}$ ( $\mathrm{F}>0$ accounting for net benefits and $\mathrm{F}<0$ for net losses) were placed along the secondary (right) vertical axis of Figure 3a, while the estimated I, Y and IWUE/IWUE $E_{R E F}$ values must be read on the principal (left) vertical axis The financial expectations seem correlated with IWUE values and quite independent of the I values, this point being further investigated. Figure 3 a provides a first indication of the dispersion of model results in response to the evolution ranges listed in Table 2. The mean values for the tests were $\mathrm{I}=366 \mathrm{~mm}, \mathrm{Y}=15.4$ ton $\mathrm{ha}^{-1}$ and IWUE $=28.1 \mathrm{~kg} \mathrm{ha}^{-1} \mathrm{~mm}^{-1}$, i.e. a comparable yield with far less irrigation, thus a better irrigation water use efficiency. This is a first indication that optimisation can be useful for the selected model and context.

Figure $3 \mathrm{~b}, \mathrm{c}, \mathrm{d}$ and e focuses on the I, Y, IWUE and $\mathrm{F}$ variables, respectively. The strong correlation between IWUE and F will be discussed several times in the manuscript. All tested parameters (of the $\mathrm{P}, \mathrm{S}$ or $\mathrm{T}$ categories) and management controls (of the $\mathrm{M}$ category) are represented by the codes indicated in Table 2 . On the $\mathrm{X}$-axis, the $\mu^{*}$ sensitivity measure gives the mean sensitivity: $(\delta \mathrm{M} / \delta \mathrm{p})$ obtained when comparing the increment $(\delta)$ in model result $(\mathrm{M})$ with that in a given parameter value (p), screening the parameter space as suggested by Campolongo et al. (2007). This $\mu^{*}$ value may thus be associated with the global individual effect of the parameter on the selected model output. On the $\mathrm{Y}$-axis, the $\sigma$ sensitivity measure states the non-linear (or interactive) effects of a given parameter on 
the selected model result, i.e. the effects obtained when variations of this parameter are tested in combination with variations of at least one other parameter. Parameters with negligible effects on I, Y, IWUE or F are very near the $(0,0)$ position in the lower left of Figure $3 b, c, d$ or e, respectively, thus hidden in the shaded areas. Parameters associated with dominant linear effects are below the 1:1 line while parameters mostly characterized by non-linear effects are above this line. The sensitivities are normalized by the maximum sensitivity measure for all tested parameters or controls $(\mathrm{P}, \mathrm{S}, \mathrm{T}$ or A categories) in the $[0,1]$ interval. Although not directly intended, Figure 3 displays sensitivity indications that hold for full irrigation but also for deficit irrigation, as I values ranged between 156 and $546 \mathrm{~mm}$, covering a wide variety of cases.

The sensitivity maximum for I, Y, IWUE and F respectively is the $\sigma$ value for the M7 management control, the threshold value of the predicted root zone reserve under which irrigation is triggered. This is an expected result for biophysical as well as for logical reasons, as this parameter indicates what is understood as the lower limit of the acceptable soil water reserve which directly dictates the decision to irrigate or not (thus with an impact on all variables more or less directly related to irrigation). For the $\mathrm{F}$ variable this parameter has equally high linear $\left(\mu^{*}\right)$ and non-linear $(\sigma)$ sensitivity scores, whereas the non-linear score prevails for the other target variables, and sensitive parameters. Together with M7, the S4 (field capacity), S5 (wilting point), M6 (sowing day) and P10 (shape parameter that describes the rise of the LAI index with accumulated temperature) combined parameters are the most sensitive for each of the I, Y, IWUE and F variables. This acknowledges the existence of strong interactions between the most sensitive model parameters, which is often a clue of oversimplified descriptions with too few parameters but here the interacting parameters belong to several categories (soil S4, soil-plant S5, plant P10 and management controls M6 and M7) with known combined effects on the target agricultural variables. It constitutes an indication that optimisation is needed and will involve adjustments in several key parameters, resulting in significant effects on model predictions.

On the one hand strong interactions between parameters means there is a risk of equifinal combinations of sensitive model parameters, for non-optimal and maybe for nearly optimal parameter sets. On the other hand, there are two parameters (M6, M7) associated with management controls (irrigation strategies) in the list of sensitive parameters, which suggests that the optimisation of irrigation strategies will greatly influence the management variables I, Y, IWUE and F. This is clearly a good point as it suggests powerful management controls (and these can hopefully be optimized). In particular, Fig. 3a indicates several interesting correlations between moderate to low I values, high IWUE values and high $\mathrm{F}$ expectations, for medium $\mathrm{Y}$ values (i.e. a zoom on the highest $\mathrm{F}$ values in Fig.3a would reveal they are most often associated with the highest IWUE values and not with high I and $\mathrm{Y}$ values - sorting the results by increasing F values would outline this point). Accordingly, the 
next uncertainty analysis section examines the relative magnitude of this poor correlation between IWUE and F on one side and I and Y on the other side. The purpose of uncertainty analysis is to provide guidance on how to sufficiently reduce the parameter uncertainties to guarantee a reliable optimisation process. Besides the sensitive parameters already mentioneda few others were found influential on I, IWUE and/or F only. These were kept for the next stages and marked with the * symbol in Table 2 . 

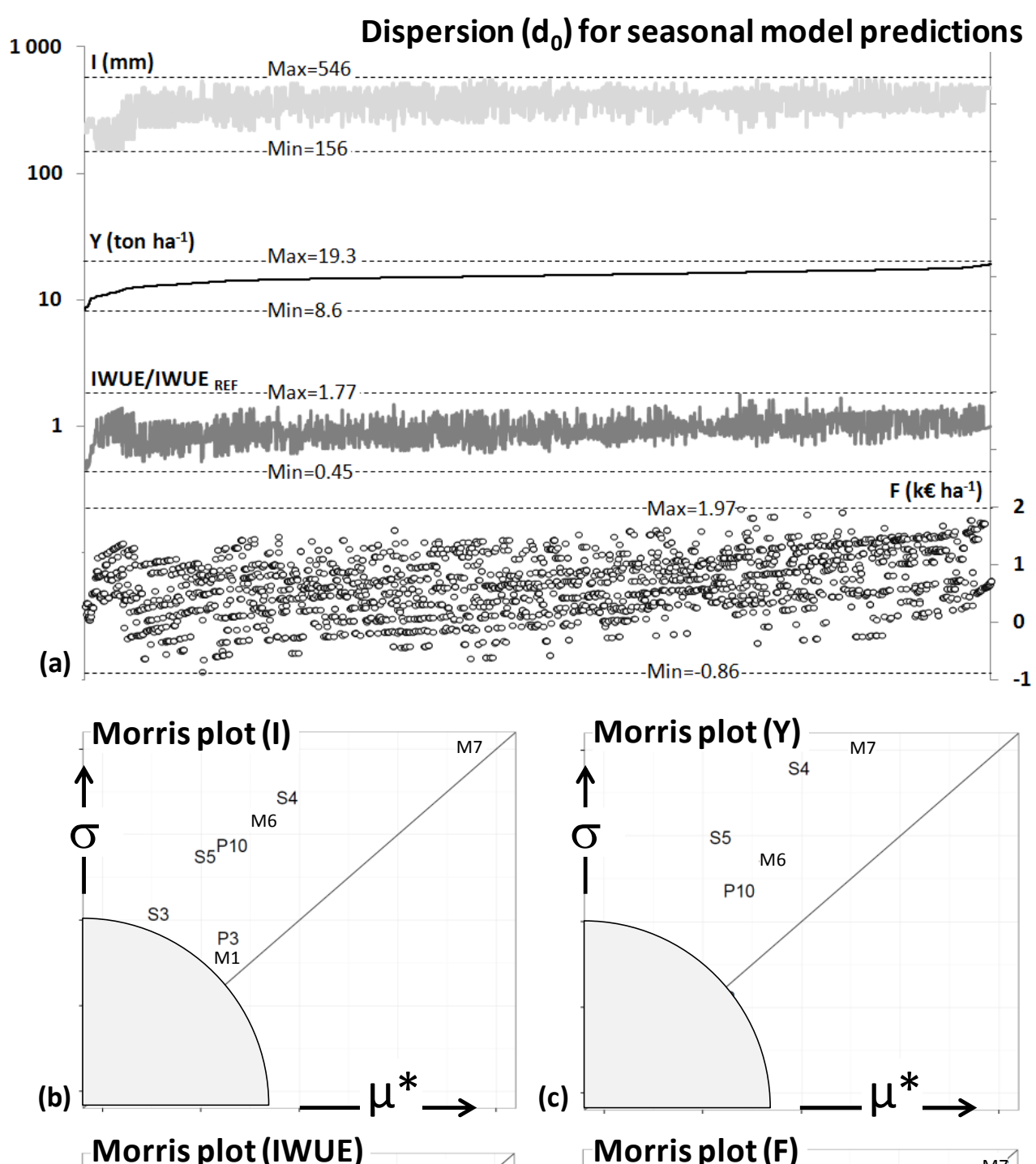

(c)
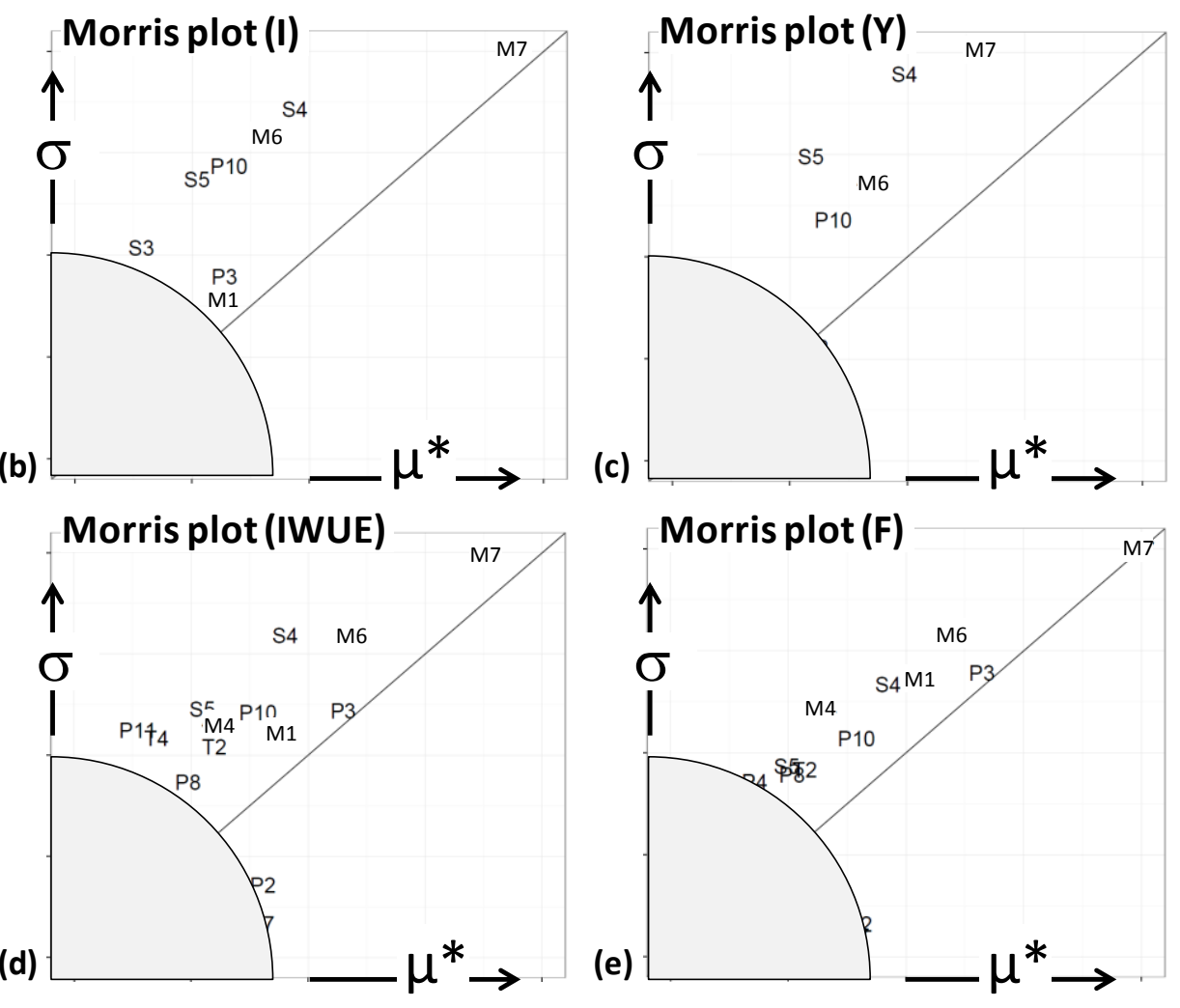

Figure 3 - Results of the sensitivity analysis runs of the framework, applied here to the Optirrig model. The sub-plot (a) shows the $d_{0}$ dispersion of the seasonal model predictions (total irrigation amount $\mathbf{I}$, crop yield $\mathrm{Y}$, irrigation water use efficiency and financial expectations F) obtained from the screening of the parameter space (Morris 1991, Campolongo et al. 2007), plotting all 2900 runs and organizing results by increasing values of Y. The other sub-plots show the sensitivity charts for the total irrigation amount $I(b)$, the crop yield $Y$ (c), the irrigation water use efficiency IWUE (d) and the financial expectations F (e), where the $\mu^{*}$ and $\sigma$ sensitivity measures indicate whether a given parameter has a dominant linear $\left(\mu^{*}\right)$ or non-linear effect $(\sigma)$ on the target variables. The (user-defined) low 
sensitivity regions have been shaded in grey. The codes used for the parameters and their variation ranges are indicated in Table 2.

\subsection{Uncertainty analysis runs}

The uncertainty analysis allows the original $d_{0}$ dispersion of model results to be reduced to $d_{1}<d_{0}$ by reducing the uncertainties in the sensitive model parameters of the $\mathrm{P}(\mathrm{P} 2, \mathrm{P} 3, \mathrm{P} 8, \mathrm{P} 10$ and P11), S (S3, S4, S5) and T (T2, T4) categories. For simplicity and to illustrate the present framework, all sensitive parameters (either from literature, calibration or field measurement type) were assumed accessible and their uncertainties could be reduced, at a certain fixed cost (termed $F_{1}$ as it is associated with the $d_{1}$ dispersion) that directly affects the $\mathrm{F}$ value of the target financial expectations thus the overall optimisation process. This $\mathrm{F}_{1}$ cost depends on the gain in precision needed on parameter values, which in turn depends on the precision deemed acceptable on one or several of the model predictions. It is crucial to understand that failure cases may exist, meaning that optimisation becomes impossible or doubtful, either when $F_{1}$ becomes non-negligible before $F$ (e.g. costly measurements) or when the uncertainty on one or several of the sensitive parameters cannot be reduced (e.g. non-observable parameters). Consequently, the proposed framework can also be used as a warning that optimisation might fail or be "weak", i.e. only possible with less numerous or less severe constraints.

For the present case, the requirements were a standard deviation of less than 1 ton $\mathrm{ha}^{-1}$ on the predicted yield values, together with a $95 \%$ confidence interval of less than $25 \%$ of the mean predicted yield values. In the textbook case tackled here, reducing the original uncertainties by half on the most sensitive parameters was enough to meet these criteria (and also realistic because the ranges indicated in Table 2 were rather wide). For example, a better determination of P3 (maximal value of the crop coefficient) and S4 (field capacity) was especially influential on the dispersion of the predicted $\mathrm{F}$ values (financial expectations). In the general case, the combination of sensitivity and uncertainty analysis runs helps deciding where to put the (financial) measurement efforts and if it is "worth the try", that is, if the additional $\mathrm{F}_{1}$ measurement costs are balanced by significant increases in $\mathrm{F}$.

Figure 4a and $\mathrm{c}$ shows the associated dispersion for three daily model predictions (RATIO, LAI and TDM) and four seasonal model predictions (I, Y, IWUE, F). The latter show dispersions significantly lower in Fig.4c than in Fig.3a, which satisfies the recommendations $\left(\mathrm{d}_{1}<\mathrm{d}_{0}\right)$ from Table 1. Indications on the transmission of uncertainties through the model can be found in the comparison between the average relative dispersions (standard deviation/mean, in \%) on RATIO (7\%), LAI (24\%) and TDM (17\%, all calculated for LAI>0.5) and on I (10\%), Y (7\%), IWUE (7\%) and F (17\%). For simplicity 
the $\mathrm{F}$ values shown in Fig.4c do not take into account the additional $\mathrm{F}_{1}$ costs, but these should certainly be kept throughout the remaining stages of the optimisation procedure.

Fig. $4 \mathrm{~b}$ and $\mathrm{d}$ show the dispersion associated with both the reduced uncertainties and the effects of deliberate irrigation strategies, simulated through multiple combinations of the irrigation parameters, within the ranges indicated in Table 2. The relative dispersions on RATIO (14\%), LAI (40\%) and TDM (25\%) in Fig.4b largely exceed these of Fig.4a, which in turn causes higher relative dispersions on I (23\%), Y (9\%), IWUE (16\%) and F (61\%) in Fig.4d than in Fig.4c. Again, the recommendations $\left(d_{2}>d_{1}\right)$ of Table 1 are met. Moreover, the fact that $d_{2} \approx d_{0}$ for most variables (with the exception of $Y$ ) suggests a favourable case where the optimisation process is needed and expected to perform well. These statistical indications are confirmed by the elements present in Fig.4d: even if there seems to be a weak correlation between the I and Y signals, there is obviously none between $\mathrm{Y}$ and F, preventing any straightforward optimisation. In contrast, the peaks in F and IWUE seem to occur for the same parameter sets, which suggests IWUE can be a good indicator for financial expectations in this model (and this is a trend known from literature, that becomes even more crucial in water scarcity contexts).

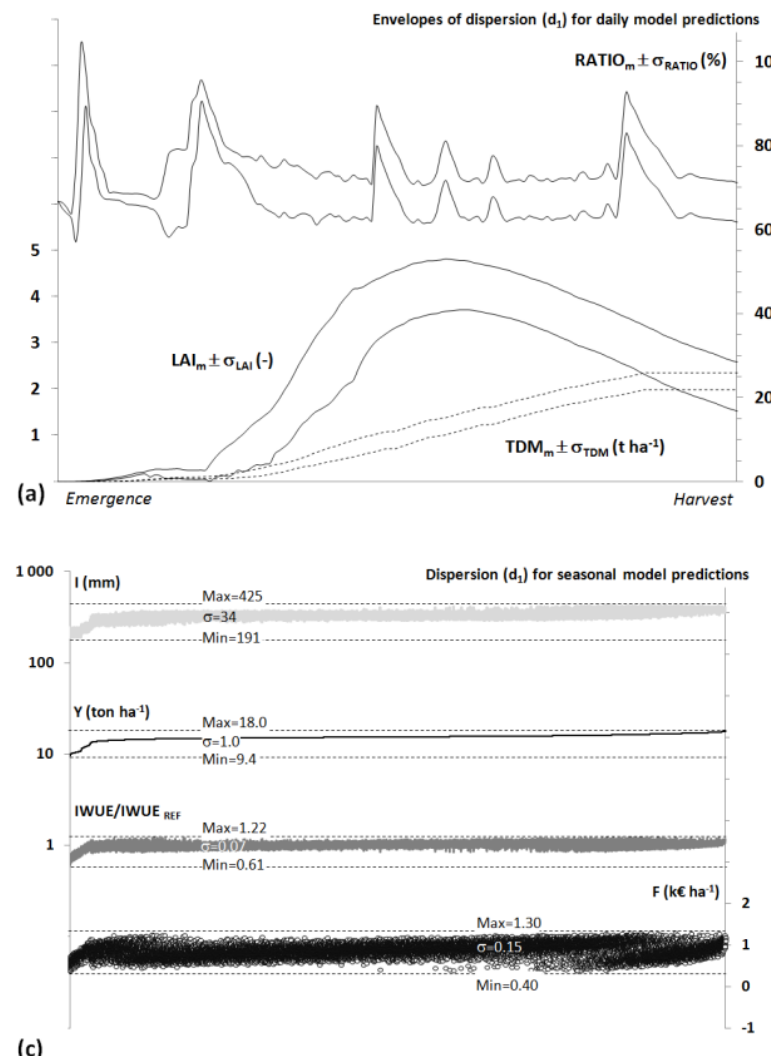

(c)

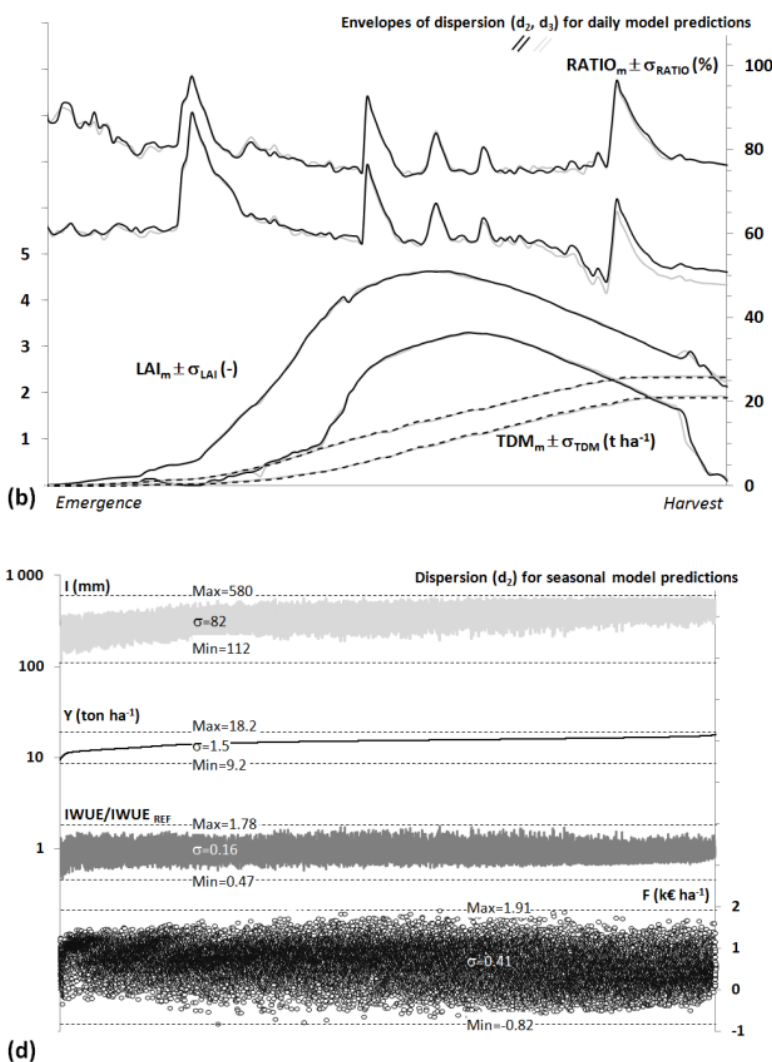

(d)

Figure 4 - Dispersion plots obtained from the uncertainty analysis runs of the framework, applied to the Optirrig model. Sketch (a) shows the $d_{1}$ dispersion on daily model predictions, testing reduced uncertainties on the sensitive model parameters. Sketch (b) shows the "obtainable" $d_{2}$ dispersion on daily model predictions, testing reduced 
uncertainties on the sensitive model parameters combined with multiple possible irrigation strategies. Sketch (b) also shows the $d_{3}$ dispersion that identifies additional effects of uncertainties on the irrigation strategies. The dispersion envelopes have been calculated as the daily mean \pm one standard deviation of the predicted LAI (Leaf Area Index), RATIO (percentage of filling of the root zone reserve) and TDM (total dry matter) values $\left(10^{5}\right.$ model runs). Sketches (c) and (d) show the $d_{1}$ and $d_{2}$ dispersions, respectively, on seasonal model predictions $I$ (total irrigation amount), $Y$ (crop yield), IWUE (irrigation water use efficiency, compared to the reference value) and F (financial expectations).

\subsection{Constrained optimisation runs}

This last part of the framework consists in identifying the optimal irrigation strategies, i.e. the combinations of values of the sensitive irrigation parameters, for which the optimisation constraints are met, here $\mathrm{I}<\mathrm{I}_{\mathrm{C}}=200 \mathrm{~mm}, \mathrm{Y}>\mathrm{Y}_{\mathrm{C}}=14$ ton $\mathrm{ha}^{-1}$ and $\mathrm{F}>\mathrm{F}_{\mathrm{C}}=1 \mathrm{k} € \mathrm{ha}^{-1}$. More than $10^{5}$ model runs were used to test random combinations of the four sensitive irrigation parameters (M1, M4, M6 and M7) and extract the optimal ones, which was followed by a back calculation for verification. The values of the irrigation parameters M4 (days after sowing used for irrigation), M6 (sowing day) and M7 (threshold value of RATIO that triggers irrigation, where RATIO is the filling percentage of the root zone reserve) are assumed to be free from uncertainty. By contrast, a $\pm 25 \%$ uncertainty affects M1 (irrigation amount), responsible for the $\mathrm{d}_{4}$ dispersion in model predictions (I, Y, IWUE and F), the latter calculated from 1000 random draws of M1 in the indicated range. This dispersion indicator allows examining the robustness of the optimal solutions. Figure 5a shows the 11 irrigation parameters sets associated with optimal irrigation strategies (including uncertainty in the irrigation amount). Figure $5 b$ shows the values of the predicted variables (with their $\mathrm{d}_{4}$ dispersion).

The results have been sorted by increasing sowing days, as this model parameter accounts for the initial decision in the category of management controls, possibly conditioning the remaining site management options. It is striking in Fig.5a that different irrigation strategies can still be used even for delayed sowing dates (at least in the tested range of sowing days and for the optimisation constraints specified). Another point is the existence of different optimal strategies for the same sowing day (e.g. M6=107), with equifinality between parameter sets [2] (M1=40 mm, M4=135 days and M7=65\%) and [3] (M1=28 mm, M4=158 days and M7=70\%). This is a plausible result as it is known from practitioners that several different irrigation strategies may provide similar results, especially for drought tolerant varieties, which leaves the possibility to decide irrigation strategies in function of external constraints (not mentioned here).

In Fig.5b, the back-calculated $\mathrm{d}_{4}$ dispersion is weak for all variables and all [1-11] solutions, as the standard deviation stays between 0.5 and $5 \%$ of the mean predicted values, even when considering a 
non-negligible $\pm 25 \%$ uncertainty on the irrigation amount, which is here the only irrigation management parameter subject to uncertainties. Figure $5 b$ therefore shows first that the most sensitive irrigation parameter (M7, Fig.3) has a narrower range of "admissible", optimal values and second that the irrigation amount (and associated uncertainties) only plays a secondary role in deciding when it is the next time to irrigate. It is likely that this would become questionable when less water is available, for example for deficit irrigation purposes. Finally, the low $d_{4}$ values in Fig.5b tend to confirm the robustness of the optimisation process. However, most of the upper limits of the predicted I values are above $I_{C}=200 \mathrm{~mm}$, certainly because $I_{C}$ was the most severe of the three constraints: either this constraint can be relaxed or the uncertainty on irrigation amounts should be further reduced.
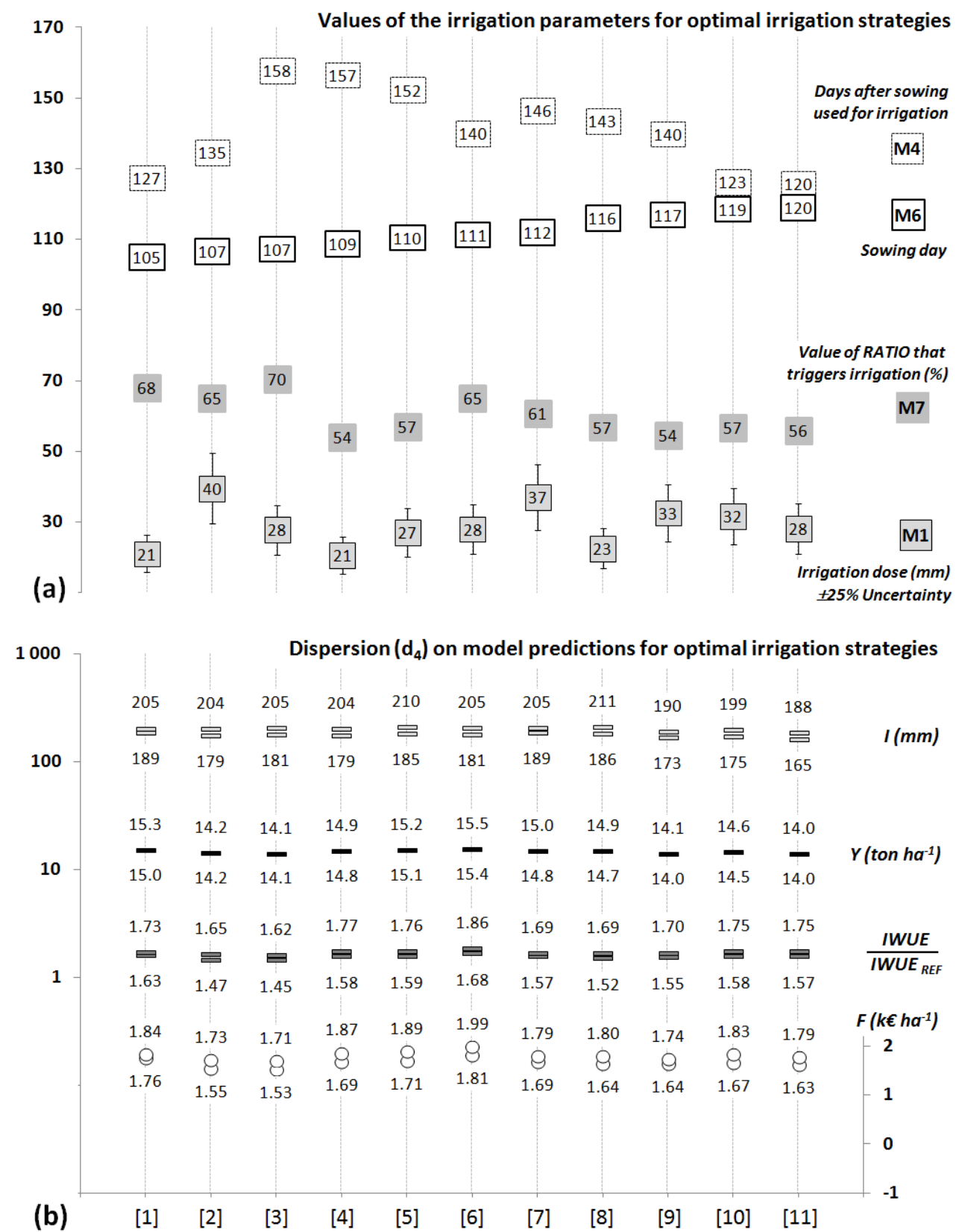
Figure 5- Results of the multi-objective constrained optimisation, showing the [1] to [11] optimal sets of irrigation parameters (M1: irrigation dose in $\mathbf{m m}$ with a $\pm 25 \%$ uncertainty, M4: period allowed for irrigation, in days after sowing, M6: sowing day and M7: water reserve RATIO that triggers irrigation, in \%) (a) and the associated values of the predicted total irrigation amount I, crop yield Y, irrigation water use efficiency IWUE (in comparison with the reference case) and financial expectations $F(b)$. The dispersion on I, Y, IWUE/IWUE $E_{R E F}$ and $F$ is the mean value of the prediction \pm one standard deviation, calculated from 1000 random draws of $\mathrm{M} 1$ within the indicated range of uncertainty. The optimisation constraints were $I<I_{C}=200 \mathrm{~mm}, Y>Y_{C}=14 \mathrm{tha}^{-1}$ and $F>F_{C}=1 \mathrm{k}$ ha $^{-1}$. Results [1] to [11] were sorted by increasing sowing days (M6 values). The allowed ranges and reference parameter values appear in Table 2. The values of model predictions can be compared with their theoretical limits in Fig.4d.

\subsection{Discussion}

\subsubsection{Specifics, strengths and limitations of this framework}

In comparison with the cited literature, the two main characteristics of this framework are to rely on causal series of direct calculations to identify optimal irrigation strategies (usually evaluated from inverse calculations) and to take advantage of the associated dispersion scores to do so (instead of minimizing an objective function).

- In the organized succession of sensitivity, uncertainty and constrained optimisation run series, the three stages are structurally independent but closely related from a conceptual point of view, as they form a whole: the originality of the framework lies thus both in the presence of all three stages and in their user-defined articulation. The latter point allows multiple degrees of freedom to address the optimization problem but it should be kept in mind that the present procedure is suitable for alreadyvalidated models only (though possibly adaptable for model verification purposes). So each stage is freely designed to exploit at best the existing knowledge (e.g. admissible parameter ranges and combinations in sensitivity analysis), information drawn from the previous stages (e.g. the sensitive parameters or climatic forcings on which uncertainty can and should be reduced to ensure profitable irrigation strategies) or for self-evaluation of the final results (e.g. the expected effects of the irreducible uncertainties on irrigation management controls: do they endanger the otherwise optimal solutions?).

- None of these stages currently occurs in parameter estimation tools or toolboxes, which arises from the choice of dispersion values as the quantities of interest. However, this choice neither excludes the use of softwares intended for inverse procedures (e.g. the popular PEST software, Doherty 2004) nor that of the many sophisticated inverse methods suitable for ill-posed problems in environmental sciences (e.g Tarantola 2005, Aster et al. 2012) but their implementation and inclusion in the present 
framework would have made it much more complex. By contrast, the objective here is to propose one of the simplest possible frameworks able to assess the feasibility of optimization and to provide guidance..

\subsubsection{Using this framework for decision support}

Whatever the tested crop model and its specifics, the presented framework aims at identifying which would have been the best irrigation strategies, in retrospect, for given climatic conditions, uncertainties and constraints. However, switching from a backward analysis of irrigation management to real-time recommendations is not straightforward, due to the unpredictability of the climate. From the sowing day on, the successive errors in climatic forecasts likely lead to sub-optimal strategies. The loss in optimality depends on the succession and magnitude of forecasting errors, which, in turn, depend on the horizon of the predictions (typically, from a few days to a week) to decide whether to irrigate or not. This dictates the temporal structure of the problem, suggesting a discretization step $\delta \mathrm{t}$ of a few days, which de facto becomes the time step of the proposed analysis, that only involves values of the state variables calculated at times that are multiples of $\delta$ t. The daily variables (LAI, TDM in Optirrig) may then be used instead of the uncalculated yet seasonal variables (I, Y, IWUE, F in Optirrig), for example by (i) assuming the objective is to minimize the difference between the best possible (e.g. $\mathrm{LAI}^{*}$ ) and the actual (e.g. LAI) values and (ii) re-examining this difference at time intervals equal to the horizon of climate forecast. Then the existence of strong discrepancies between LAI and LAI* suggests changing the rules, i.e. either the values of the sensitive parameters in the $\mathrm{M}$ category, or the confidence placed in the climate forecast, or both.

For most crop models, the seasonal variables IWUE and F may write IWUE (Y, I) and F(Y, I), while $\mathrm{Y}$ is $\mathrm{Y}(\mathrm{p}, \mathrm{LAI}, \mathrm{TDM})$. Any $\delta \mathrm{LAI}$ change in LAI values results in a $\delta \mathrm{Y}$ change in $\mathrm{Y}$, so that $\delta \mathrm{Y}=\delta \mathrm{Y}(\mathrm{p}$, $\delta \mathrm{LAI}, \mathrm{TDM})$. Whatever the structure of the crop model, taking $\delta \mathrm{LAI}=\mathrm{LAI} * \mathrm{LAI}$ allows anticipating $\delta \mathrm{Y}=\mathrm{Y}^{*}-\mathrm{Y}, \delta \mathrm{IWUE}=\mathrm{IWUE}{ }^{*}$-IWUE and $\delta \mathrm{F}=\mathrm{F}^{*}-\mathrm{F}$ provided this anticipation relies on a sufficient, statistically significant number of cases (or, equivalently, on a well-known model behaviour). This condition is met by constituting a large library of cases assembled from past real and synthetic situations, crossing multiple climate types (especially rain amounts, still within the proposed temporal discretization) with plausible values of the management controls, to simulate decision rules and their expected effects. The added value of this procedure is that decision rules may be changed not only as a function of the current daily values of LAI or TDM, but also based on the anticipated values of the seasonal variables, plausibly with more precision as the season advances but with larger sensitivity in the early crop growth periods. 
The ability of any automated model to produce or reproduce scenarios for diagnostic purposes makes it compatible with machine learning techniques, especially those of artificial intelligence (neuronal networks, evolutionary algorithms). After the diagnostic work (the ex-post optimisation described here) the next step could be the re-examination of the database to directly address and improve the decision rules, with the objective to provide better real-time recommendations in the future.

\section{Conclusion}

The existence of uncertainties in model parameters and climatic forcings should not be ignored, neither should model predictions be unqualified by the associated error terms, confidence intervals or statistical dispersion envelopes. The latter prove relevant when dealing with random uncertainties, which in turn requires numerous model runs to gain meaningful insights on the propagation of uncertainties through the model. In most crop models, the uncertainties on source data propagate to the daily (water reserve, leaf area index LAI, total biomass) then to the seasonal model variables, eventually resulting in dispersion on the key model predictions (here, the total irrigation amount I, crop yield $\mathrm{Y}$, the irrigation water use efficiency IWUE and financial expectations $\mathrm{F}$ ). Large dispersions question the feasibility and relevance of optimisation processes as they mean too little is known about the variables to optimise. The purpose of the present framework is to guide the modeller through successive run series (sensitivity analysis, uncertainty analysis, optimisation runs) to gather the conditions of a reliable constrained optimisation of irrigation strategies. In its present form, this framework is relevant for constrained optimisation but should not be used for model verification purposes, at least when relying on a single test case: this framework therefore applies to models already validated, as the Optirrig model here (the former PILOTE model expanded with automation procedures and additional output variables).

The framework calculates four levels of dispersion to assess the impacts of uncertainties in parameters, irrigation strategies and irrigation parameters as well as the remaining uncertainty after optimisation relative to the base case. This allows identifying several optimal though very different combinations of irrigation parameters (sowing day, duration of the period used for irrigation, irrigation dose and trigger) which illustrates its possibilities in cases where the result is not straightforward. This also leaves the possibility to decide relevant, near-optimal irrigation strategies in function of additional constraints either known (e.g. water turns) or anticipated (e.g. irrigation restrictions by prefectural decree), or even external to this framework (e.g. availability of the workforce). The identification of 
equifinal parameter sets in association with the user-defined system of inequalities on the target variables is an outcome of the present study.

\section{$5 \quad$ Acknowledgements}

[to be completed] 


\section{References}

Aggarwal, P. K. (1995). Uncertainties in crop, soil and weather inputs used in growth model: implications for simulated outputs and their applications, Agricultural Systems, 48, pp.361-384.

Asseng, S., Ewert, F., Rosenzweig, C., Jones, J.W., Hatfield, J.L., Ruane, A.C., Boote, K.J., Thorburn, P.J., Rotter, R.P., Cammarano, D., Brisson, N., Basso, B., Martre, P., Aggarwal, P.K., Angulo, C., Bertuzzi, P., Biernath, C., Challinor, A.J., Doltra, J., Gayler, S., Goldberg, R., Grant, R., Heng, L., Hooker, J., Hunt, L.A., Ingwersen, J., Izaurralde, R.C., Kersebaum, K.C., Muller, C., Naresh Kumar, S., Nendel, C., O'Leary, G., Olesen, J.E., Osborne, T.M., Palosuo, T., Priesack, E., Ripoche, D., Semenov, M.A., Shcherbak, I., Steduto, P., Stockle, C., Stratonovitch, P., Streck, T., Supit, I., Tao, F., Travasso, M., Waha, K., Wallach, D., White, J.W., Williams, J.R. and Wolf, J. (2013). Uncertainty in simulating wheat yields under climate change, Nature Climate Change, 3(9), pp.827-832.

Aster, R. C., Thurber, C. H. and Borchers, B. (2012). Parameter estimation and inverse problems, Second Edition, Amsterdam: Elsevier Academic Press, 360p.

Belcher, K. W., Boehm, M. M. and Fulton, M. E. (2004). Agroecosystem sustainability: a system simulation model approach, Agricultural Systems, 79, pp.225-241.

Bergez, J.-E., Chabrier, P., Gary, C., Jeuffroy, M.H., Makowski, D., Quesnel, G., Ramat, E., Raynal, H., Rousse, N., Wallach, D., Debaeke, P., Durand, P., Duru, M., Dury, J., Faverdin, P., GascuelOdoux, C. and Garcia, F. (2013). An open platform to build, evaluate and simulate integrated models of farming and agro-ecosystems. Environmental Modelling \& Software, 39, pp.39-43.

Berntsen, J., Petersen, B. M., Jacobsen, B. H., Olsen, J. E. and Hutchings, N. J. (2003). Evaluating nitrogen taxation scenarios using the dynamic whole farm simulation model FASSET, Agricultural Systems, 76 (3), pp.817-839.

Boogaard, H. L., van Diepen, C.A., Roetter, R.P., Cabrera, J. M. C. A. and van Laar, H.H. (1998). WOFOST 7.1 : user's guide for the WOFOST 7.1 crop growth simulation model and WOFOST Control Center 1.5. Technical document / DLO Winand Staring Centre, Wageningen.

Brisson, N., Gary, C., Justes, E., Roche, R., Mary, B., Ripoche, D.,Zimmer, D., Sierra, J.,Bertuzzi, P., Burger, P., Bussière, F., Cabidoche, Y.M., Cellier, P., Debaeke, P., Guadillère, J.P., Hénnault, C., Maraux, F., Seguin, B. and Sinoquet, H. (2003). An overview of the crop model STICS, European Journal of Agronomy, 18, pp.309-332. 
Brisson, N., Launay, M., Mary, B. and Beaudoin, N. (2009). Conceptual basis, formalisations and parameterizations of the STICS crop model, Editions Quae, Versailles, France, Collection Update Sciences and Technologies, pp.141-165.

Brown, H. E., Huth, N. I., Holzworth, D. P., Teixeira, E. I., Zyskowski, R. F., Hargreaves, J. N. G. and Moot, D. J. (2014) Plant Modelling Framework: software for building and running crop models on the APSIM platform, Environmental Modelling \& Software, 62, pp.385-398.

Campolongo, F. and Saltelli, A. (1997). Sensitivity analysis of an environmental model: an application of different analysis methods, Reliability Engineering and System Safety, 57 (1), pp.49-69.

Campolongo, F., Cariboni, J. and Saltelli, A. (2007). An effective screening design for sensitivity analysis of large models, Environmental Modelling and Software, 22, pp.1509-1518.

Cetin, O. and Uygan, D. (2008). The effect of drip line spacing, irrigation regimes and planting geometries of tomato on yield, irrigation water use efficiency and net return, Agricultural Water Management, 95 (8), pp.949-958.

Challinor, A.J., Wheeler, T., Hemming, D. and Upadhya, H.D. (2009). Ensemble yield simulations: crop and climate uncertainties, sensitivity to temperature and genotypic adaptation to climate change, Climate Research, 38, pp.117-127.

Challinor, A.J., Simelton, E.S., Fraser, E.D.G., Hemming, D. and Collins, M. (2010) Increased crop failure due to climate change: assessing adaptation options using models and socio-economic data for wheat in China, Environmental Research Letters, 5, doi: 10.1088/1748-9326/5/3/034012

Constantin, J., Willaume, M., Murgue, C., Lacroix, B. and Theron, O. (2015). The soil-crop models STICS and AqYield predict yield and soil water content for irrigated crops equally well with limited data, Agricultural and Forest Meteorology, 206, pp.55-68.

de Wit, A. (2015). PCSE Documentation, Release 5, 80p.

Available online at https://media.readthedocs.org/pdf/pcse/latest/pcse.pdf

Doherty, J. (2004). PEST: Model-independent parameter estimation. User manual. 5th ed. Watermark Numerical Computing, Brisbane, QLD, Australia. 
Duchemin, B., Hadria, R., Erraki, S., Boulet, G., Maisongrande, P., Chehbouni, A., Escadafal, R., Ezzahar, J., Hoedjes, J.C.B., Kharrou, M.H., Khabba, S., Mougenot, B., Olioso, A., Rodriguez, J.C. and Simonneaux, V. (2006). Monitoring wheat phenology and irrigation in Central Morocco: on the use of relationships between evapotranspiration, crops coefficients, leaf area index and remotely-sensed vegetation indices, Agricultural Water Management, 79 (1), pp.1-27.

Duchemin, B., Maisongrande, P., Boulet, G. and Benhadj, I. (2008). A simple algorithm for yield estimates: evaluation for semi-arid irrigated winter wheat monitored with green leaf area index, Environmental Modelling \& Software, 23 (7), pp.876-892.

English, M. (1990). Deficit irrigation. I. Analytical framework, Journal of Irrigation and Drainage Engineering ASCE, 116, pp.399-412.

Feng, L., Mailhol, J.-C, Rey, H., Griffon, S., Auclair, D. and De Reffye, P. (2014). Comparing an empirical crop model with a functional structural plant model to account for individual variability, European Journal of Agronomy, 53, pp.16-27.

Janssen, S. and van Ittersum, M. (2007). Assessing farm innovations and responses to policies: a review of bio-economic farm models, Agricultural Systems, 94, pp.622-636.

Jones, J. W., Hoogenboom, G., Porter, C. H., Boote, K. J., Batchelor, W. D., Hunt, L. A., Wilkens, P. W., Singh, U., Gijsman, A. J. and Ritchie, J. T. (2003). DSSAT Cropping System Model, European Journal of Agronomy, 18, pp.235-265.

Gan, Y., Duan, Q., Gong, W., Tong, C., Sun, Y., Chu, W. Ye, A., Miao, C. and Di, Z. (2014). A comprehensive evaluation of various sensitivity analysis methods: A case study with a hydrological model, Environmental Modelling \& Software, 51, pp.269-285.

García-Vila, M. and Fereres, E. (2012). Combining the simulation crop model AquaCrop with an economic model for the optimization of irrigation management at farm level, European Journal of Agronomy, 36 (1), pp.21-31.

Gaudou, B., Sibertin-blanc, C., Therond, O., Amblard, F., Arcangeli, J., Balestrat, M., Sauvage, S. and Taillandier, P. (2013). The MAELIA multi-agent platform for integrated assessment of low-water 
management issues, in: MABS 2013 -14th International Workshop on Multi-Agent-Based Simulation. Saint Paul, Minnesota, pp. 1-12.

Geerts, S. and Raes, D. (2009). Deficit irrigation as an on-farm strategy to maximize crop water productivity in dry areas, Agricultural Water Management, 96, pp.1275-1284.

Hanson, J. D., Ahuja, L. R., Shaffer, M. D., Rojas, K. W., DeCoursey, D. G., Farahani, H. and Johnson, K. (1998). RZWQM: simulating the effects of management on water quality and crop production, Agricultural Systems, 57 (2), pp.161-195.

HarvestChoice (2010). Generic Soil Profiles for Crop Modeling Applications (HC27), International Food Policy Research Institute, Washington, DC., and University of Minnesota, St. Paul, MN. Available online at http://harvestchoice.org/node/662.

Heinemann, A. B., Hoogenboom, G. and Chojnicki, B. (2002). The impact of potential errors in rainfall observation on the simulation of crop growth, development and yield, Ecological Modelling, 157, pp.1-21.

Helton, J. C. (1993), Uncertainty and sensitivity analysis techniques for use in performance assessment for radioactive waste disposal, Reliab. Eng. Syst. Safety, 42, 327-367.

Islam, A., Ahuja, L. R., Garcia, L. A., Ma, L., Saseendran, S. A. and Trout, T. J. (2012). Modelling the impact of climate change on corn yield using multi-model ensemble climate change scenarios, Agricultural Water Management, 110, pp.94-108.

Jarvis, N. J. and Larsbo, M. (2012). MACRO (V5.2): Model use, calibration, and validation, Transactions of the American Society of Agricultural and Biological Engineers, 55 (4), pp.1413-1423.

Kandelous, M. M. and Simunek, J. (2010). Numerical simulations of water movement in a subsurface drip irrigation system under field and laboratory conditions using HYDRUS-2D, Agricultural Water Management, 97 (7), pp.1070-1076.

Keating, B.A., Carberry, P.S., Hammer, G.L., Probert, M.E., Robertson, M.J., Holzworth, D., Huth, N.I., Hargreaves, J.N.G., Meinke, H., Hochman, Z., McLean, G., Verburg, K., Snow, V., Dimes, J.P., Silburn, M., Wang, E., Brown, S., Bristow, K.L., Asseng, S., Chapman, S., McCown, R.L., Freebairn, 
D.M. and Smith, C.J. (2003). An overview of APSIM, a model designed for farming systems simulation, European Journal of Agronomy, 18, pp.267-288.

Khaledian, M.R, Mailhol, J.C., Ruelle, P. and Rosique, P. (2009). Adapting PILOTE model for water and yield management under direct seeding system. The case of corn and durum wheat in mediterranean climate, Agricultural Water Management, 96, pp.757-770.

Ko, J., Ahuja, L. R., Saseendran, S. A., Green, T. R., Ma, L., Nielsen, D. C. and Walthall, C. (2011). Climate change impacts on dryland cropping systems in the central great plains, USA, Climate Change, 107: DOI 10.1007/s10584-011-0175-9.

Lubana, P. P. S. and Narda, N. (2001) Sw- Soil and water: modelling soil and water dynamics under trickle emitters - a review, Journal of Agricultural Engineering Research, 78 (3), pp.217-233.

Ludwig, F. and Asseng, S. (2006). Climate change impacts on wheat production in a Mediterranean environment in Western Australia, Agricultural Systems, 90, pp.159-179.

Ma, L., Hoogenboom, G., Ahuja, L. R., Ascough, J. C. and Saseendran, S. A. (2006). Evaluation of the RZWQM-CERES-Maize hybrid model for maize production, Agricultural Systems, 87 (3), pp.274-295.

McCown, R.L., Hammer, G.L., Hargreaves, J.N.G., Holzworth, D. and Huth, N.I. (1995). APSIM An agricultural production system simulation model for operational research, Mathematics and Computers in Simulation, 39, pp.225-231.

McKay, M.D. (1988). Sensitivity and uncertainty analysis using a statistical sample of input values. In: Ronen, Y. (Ed.), CRC Press, Boca Raton, FL, pp.145-186.

Mailhol J.C., Olufayo, O. and Ruelle, P. (1997). AET and yields assessments based on the LAI simulation. Application to sorghum and sunflower crops, Agricultural Water Management, 35, pp.167182.

Mailhol, J.C., Ruelle, P., Walser, S., Schütze, N. and Dejean, C. (2011). Analysis of AET and yield prediction under surface and buried drip irrigation systems using the crop model PILOTE and Hydrus2D, Agricultural Water Management, 98, pp.1033-1044. 
Morris, M. D. (1991). Factorial sampling plans for preliminary computational experiments, Technometrics, 33 (2), pp.161-174.

Monteith, J. L. (1996). The quest for balance in crop modeling, Agronomy Journal, 88, pp.695-697.

Murgue, C., Lardy, R., Vavasseur, V., Leenhardt, D. and Therond, O. (2014). Fine spatio-temporal simulation of cropping and farming systems effects on irrigation withdrawal dynamics within a river basin. Daniel P. Ames, Nigel W.T. Quinn and Andrea E. Rizzoli (Eds.). 7th Int. Congress on Env. Modelling and Software (iEMSs), San Diego, CA, USA, 8p.

Nolot, J.M. and Debaeke, P. (2003). Principes et outils de conception, conduite et évaluation de systèmes de culture, Cahiers de l'Agriculture, 12, pp.387-400.

Nonhebel, S. (1994). Inaccuracies in weather data and their effects on crop growth simulation results. II. Water-limited production, Climate Research, 4, pp.61-74.

Olufayo, A., Baldy, C., Some, L. and Traore, I. (1994). Tillage effects on grain-sorghum (Sorghum bicolour (L) Moench) development and plant water status in Burkina-Faso, Soil \& Tillage Research, 32 (2-3), pp.105-116.

Owen, A. B. (1992). Orthogonal arrays for computer experiments, integration and visualization, Statistica Sinica, 2 (2), pp.439-452.

Pereira, L. S., Oweis, T. and Zairi, A. (2002). Irrigation management under water scarcity, Agricultural Water Management, 57, pp.175-206.

Raes, D., Steduto, P., Hsiao, T.C. and Fereres, E. (2009). AquaCrop - the FAO crop model to simulate yield response to water. II. Main algorithms and software description, Agronomy Journal, 101, pp.438-447.

Reca, J., Roldan, J., Alcaide, M., Lopez, R. and Camacho, E. (2001). Optimisation model for water allocation in deficit irrigation systems. I. Description of the model, Agricultural Water Management, 48, pp.103-116. 
Reidsma, P., Ewert, F., Boogaard, H. and Diepen, K.v. (2009). Regional crop modelling in Europe: The impact of climatic conditions and farm characteristics on maize yields, Agricultural Systems, 100 (1-3), pp.51-60.

Rivington, M., Matthews, K. B., Bellochi, G. and Buchan, K. (2006). Evaluating uncertainty introduced to process-based simulation of model estimates by alternative sources of meteorological data, Agricultural Systems, 88, pp.451-471.

Rosenzweig, C. and Parry, M. L. (1994). Potential impact of climate change on world food supply, Nature, 367, pp.133-138.

Rötter, R. P., Carter, T. R., Olesen, J. E. and Porter, J. R. (2011). Crop-climate models need an overhaul, Nature Climate Change, 1, pp.175-177.

Rosenzweig, C., Elliott, J., Deryng, D., Ruane, A. C., Müller, C., Arneth, A., Boote, K. J., Folberth, C., Glotter, M., Khabarov, N., Neumann, K., Piontek, F., Pugh, T.A.M., Schmid, E., Stehfest, E., Yang, H. and Jones, J.W. (2014). Assessing agricultural risks of climate change in the 21st century in a global gridded crop model intercomparison, Proceedings of the National Academy of Sciences, 111 (9), pp.3268-3273.

Sieber, A., and S. Uhlenbrook (2005), Sensitivity analyses of a distributed catchment model to verify the model structure, J. Hydrol., 310, 216-235.

Singh, A. K., Madramootoo, C. A., Goyal, M. K. and Smith, D. L. (2014). Corn yield simulation using STICS model under varying nitrogen management and climate-change scenarios, Journal of Irrigation and Drainage Engineering, 140 (4), 04013023.

Sobol, I.M. (1993) Sensitivity estimates for nonlinear mathematical models, Math. Model. Comp. Exp., 1, 407-414.

Spank, U., Schwärtzel, K., Renner, M. Moderow, U. and Berhofer, C. (2013). Effects of measurement uncertainties of meteorological data on estimates of site water balance components, Journal of Hydrology, 492, pp.176-189.

Steduto, P., Hsiao, T.C., Raes, D. and Fereres, E. (2009). AquaCrop - the FAO crop model to simulate yield response to water. I. Concepts and underlying principles. Agronomy Journal, 101, pp.426-437. 
Sun, H.-Y., Liu, C.-M., Zhang, X.-Y., Shen, Y.-J. and Zhang, Y.-Q. (2006). Effects of irrigation on water balance, yield and WUE of winter wheat in the North China Plain, Agricultural Water Management, 85 (1-2), pp.211-218.

Supit, I., van Diepen, C.A., de Wit, A.J.W., Wolf, J., Kabata, P., Baruth, B. and Ludwig, F. (2012). Assessing climate change effects on European crop yields using the Crop Growth Monitoring System and a weather generator, Agricultural and Forest Meteorology, 164, pp.96-111

Taky, A., Bouarfa, S., Mailhol, J.C., Hamani, A., Ruelle, P. and Bouaziz, A. (2009). The furrow irrigation system: a technique to improve water productivity in the Gharb valley (Morocco). Irrigation and Drainage, 58, pp.297-306.

Tang, B. (1993). Orthogonal array-based Latin hypercubes, Journal of the American Statistical Association, 88 (424), pp.1392-1397.

6 Tarantola, A. (2005). Inverse problem theory and methods for model parameter estimation, SIAM, 344p., DOI: http://dx.doi.org/10.1137/1.9780898717921

van Diepen, C.A., Wolf, J. and van Keulen, H. (1989). WOFOST: a simulation model of crop production, Soil Use and Management, 5, pp.16-24.

van Griensven, A., Meixner, T., Grunwald, S., Bishop, T., Diluzio, M. and Srinivasan, R. (2006). A global sensitivity analysis tool fort he parameters of multi-variable catchment models, Journal of Hydrology, pp.10-23.

van Ittersum, M. K., Leffelaar, P. A., Van Keulen, H., Kropff, M. J., Bastiaans, L. and Goudriaan, J. (2003). On approaches and applications of the Wageningen crop models, European Journal of Agronomy, 18 (3), pp.201-234.

Vatn, A., Bakken, L., Botterweg, P. and Romstad, E. (1999). ECECMOD: an interdisciplinary modelling system for analysing nutrient and soil losses from agriculture, Ecological Economics, 30, pp.189-205.

Wallach, D., Brun, F., Keussayan, N., Lacroix, B. and Bergez, J.-E. (2012). Assessing the uncertainty when using a model to compare irrigation strategies, Agronomy Journal, 104, pp.1274-1283. 
White, J. W., Hoogenboom, G., Kimball, B. A. and Wall, G. W. (2011). Methodologies for simulating impacts of climate change on crop production, Field Crops Research, 124, pp.357-368.

Wolf, J. and van Diepen, C.A. (1995). Effects of climate change on grain maize yield potential in the European Community, Climatic Change, 29(3), pp.299-331.

Yang, J. (2011). Convergence and uncertainty analyses in Monte-Carlo based sensitivity analysis, Environmental Modelling and Software, 26 (4), pp.444-457. 